\title{
El desarrollo de la codecisión como procedimiento legislativo de la $\mathrm{UE}^{*}$
}

\author{
Enrique Barón Crespo \\ Catedrático Jean Monnet «ad personam» \\ Universidad de Castilla la Mancha (UCLM)
}

Sumario: I. Introducción. - II. Génesis del poder legislativo en la UE. II.1. La primera etapa: la Asamblea Consultiva (1952-1979). II.2. El PE elegido (1979-2011). II.2.1. 1979-1993. II.2.2. De la CE a la UE (1993-2011). - II.3. El papel del Tribunal de Justicia. II.4. El salto constituyente. - III. La codecisión legislativa. III.1. Ámbito de aplicación. III.2. Funcionamiento del procedmiento legislativo ordinario. III.2.1. Primera lectura. III.2.2. Segunda lectura. III.2.3. Conciliación.-IV. Balance de la codecisión desde el PE. - V. Relaciones con la Comisión. - VI. El legislador europeo y la esfera pública. - VII. Conclusión.

Resumen: Estudio del desarrollo de la Unión Europea como un sistema político constitucional, con un poder legislativo basado en la doble legitimidad democrática. La UE es un proceso constituyente abierto desde la CECA en el que el Tratado de Maastricht estableció la codecisión legislativa. Los poderes conferidos en el Tratado de Lisboa hacen que el Parlamento Europeo pueda ser calificado como colegislador junto al Consejo en un sistema de tres lecturas a partir de la iniciativa de la Comisión. Su balance es positivo tanto en términos cuantitativos como cualitativos de cara a la implementación del mercado interior y la protección de los derechos de los ciudadanos. La cuestión de los legisladores europeos y la esfera pública es clave para la codecisión.

Palabras clave: democracia, doble legitimidad, codecisión, legislador, esfera pública.

abstract: Study of the European Union's development into a constitutional political system, with legislative power founded on twofold democratic legitimacy. The EU is an open constituent process since the ECSC. The Maastricht Treaty, established legislative codecision. The powers conferred on it in the Lisbon Treaty are such that the EP can rightly be described as a co-legislator acting jointly with the Council in a three readings system on the initiative of the Commission. On balance, codecision has been positive in both quantitative and qualitative terms as well as with regard to the implementation and conditioning of the internal market and the protection of citizens' rights. The question of the European legislators and the public sphere is key for codecision.

Keywords: democracy, double legitimacy, codecision, legislator, public sphere.

* Recibido el 2 de diciembre de 2011, aceptado el 22 de diciembre de 2011. 


\section{Introducción}

La historia de la construcción europea es un proceso constituyente abierto, en el que un creciente grupo de Estados democráticos va configurando, mediante ampliaciones y reformas plasmadas en Tratados, una Unión Europea (UE) - Política, Económica y Monetaria-, con un poder legislativo compartido, que genera normas directamente aplicables en los ordenamientos internos de sus Estados Miembros (EE.MM.) ${ }^{1}$.

La Declaración Schuman dio comienzo en 1950 al proceso de creación de «la Federación Europea que no se haría de una sola vez sino paso a paso». Puso bajo una Alta Autoridad común la producción de carbón y acero, con las cuatro libertades fundamentales base del Mercado común: libertad de establecimiento y desplazamiento de las personas, libertad de circulación de bienes, servicios y capitales. Heterodoxa concepción, que implicaba la superación de las alianzas intergubernamentales, base del equilibrio de poderes desde la Paz de Westfalia.

Frente a la voluntad fundadora política a través de un proceso constituyente, planteada en el Congreso del Movimiento Europeo de 1948, prevaleció la línea funcionalista - avanzar paso a paso-, uniendo principios e intereses a través del original método concebido por Jean Monnet, con otros padres fundadores, Robert Schuman, Konrad Adenauer, PaulHenri Spaak, Alcide de Gasperi², para crear «unas instituciones europeas que con autoridad supranacional reconocida por los Estados y ratificada por los Parlamentos nacionales pudieran crear este espacio jurídico europeo».

La configuración de un mercado común necesitaba reglas comunes y una autoridad. Para ello, los Parlamentos de los Estados miembros (EE.MM.) confirieron poderes legislativos y ejecutivos al Consejo de Ministros (CONS) de los Gobiernos de los seis Estados fundadores a partir de propuestas de la Alta Autoridad (luego Comisión (COM)), ejecutivo colegial europeo nombrado con el monopolio de iniciativa como guardián de los

${ }^{1}$ Normas que, en ausencia de una clara jerarquía normativa, condujeron a un auténtico laberinto de fuentes del Derecho Comunitario entre las que significativamente no aparece la ley, aunque en el Diario Oficial las normas se publiquen como LEX.Fuentes obligatorias, no obligatorias, complementarias y «actos sui generis», con el Derech o originario y derivado, formado en esencia por directivas y reglamentaciones, amén de decisiones generales, individuales y sin destinatario, recomendaciones, informes, declaraciones, programas de interés común. En total, más de 30 tipos de normativa cuya única característica común es estar sometidas a la jurisprudencia del Tribunal de Justicia.

2 MARTÍNEZ HERNÁNDEZ, E., Alcide De Gasperi: Artífice de la República Italiana y del Ius Publicum Europaeum. Publicaciones Universidad Pontificia de Salamanca, 1990, p. 211. 
Tratados. El CONS tenía el poder de aprobar las propuestas de la COM por «mayoría cualificada» ponderada entre los países según su tamaño y en algunos temas, por unanimidad.

Su legitimidad provenía de que los EE.MM. eran democráticos, aunque el trabajo legislativo se hiciera por un Consejo de Ministros legislando a puerta cerrada sin registro de votaciones, justificación del voto, actas públicas, o rendición de cuentas como las existentes en cada país. Razón básica de la crítica sobre el «déficit democrático» en el sistema institucional comunitario ${ }^{3}$.

Sobre la naturaleza de la naciente Comunidad tuvo importancia histórica la Sentencia Vand Geen Loos de 1963 (caso 26/62)4 cuando llegó a la conclusión de que «la Comunidad constituye un nuevo ordenamiento jurídico de Derecho Internacional a favor del cual los Estados han limitado su soberanía, si bien en un ámbito restringido, y cuyos sujetos son no solo los EE.MM. sino también sus nacionales».

En el Tratado de la Unión Europea (TUE) de Maastricht se introdujo la codecisión legislativa «que ha pasado a ser el procedimiento legislativo ordinario en el Tratado de Lisboa, con primacía sobre el Derecho de los Estados miembros en las materias de su competencia. Con ello, la Unión Europea dio un paso sustancial para superar su inicial déficit democrático. La cuestión se plantea en torno a las condiciones necesarias para la «consolidación de una democracia supranacional en la Unión Europea» en palabras del ex Presidente del Tribunal de Justicia Europeo, Prof. Gil Carlos Rodríguez Iglesias, como «creación original entre los Estados-Nación más caracterizados de la historia» ${ }^{5}$. Por su naturaleza y contenido, la Unión Europea no es una organización internacional más. En su estadio actual, comparte características de una Federación en el campo monetario y crecientemente en el económico con elementos confederales e intergubernamentales típicos de las organizaciones internacionales clásicas.

En la situación actual de reforzamiento de la dimensión federal de la Unión Europea como respuesta a la crisis, estudiar el proceso de gestación y consolidación de la codecisión como procedimiento legislativo ordinario con activa participación de los Parlamentos de sus Estados miembros es ilustrativo acerca de uno de los desafíos fundamentales del Derecho: cómo conjugar democracia, legitimidad y eficacia

\footnotetext{
3 Informe Toussaint, de 1-2-88, PE Doc.No. A 2-276/87.

${ }^{4}$ Recopilación de Jurisprudencia (R.J.). Edición francesa de 1963 p .00003. Edición especial española, 1961-1963, p. 00333. Eur lex. eurlex-helpdesk@publications.europa.eu

${ }_{5}$ RODRÍGUEZ IGLESIAS, G.C., prólogo a mi libro Constitucionalización del poder legislativo en la Unión Europea. Ed. Thomson Civitas, p. 22.
} 


\section{Génesis del poder legislativo en la UE}

\section{II.1. La primera etapa: la Asamblea Consultiva (1952-1979)}

En la sesión inaugural de la Asamblea Parlamentaria de la CECA en 1952, Jean Monnet, como Presidente de la Alta Autoridad, afirmó que era responsable ante la «primera Asamblea Europea dotada de poderes soberanos», que con el Tribunal de Justicia y la Alta Autoridad constituía un conjunto de «instituciones supranacionales y, pronunciemos la palabra, federales». El Canciller Adenauer, como Presidente del Consejo, afirmó que «este primer Parlamento soberano establecido sobre bases supranacionales mantiene una relación con el CM comparable, en ciertos aspectos, con las relaciones entre dos Cámaras en la vida constitucional de un Estado» ${ }^{6}$.

Los Tratados de la CECA y Roma preveían la convocatoria de elecciones directas de la Asamblea, que se autodenominó Parlamento Europeo (PE) en 1962, pero prevaleció la reticencia de los gobiernos. Fue un foro de debate, compuesto por diputados elegidos a segundo nivel por sus respectivos Parlamentos, consultado previamente sobre propuestas legislativas a su aprobación por el CONS. Aunque no tenía el poder de votar la confianza a la Comisión, disponía de un teórico voto de censura con una mayoría de dos tercios. En su configuración, quedaba abierta la «cuestión democrática«, en palabras de Bino Olivi, portavoz de la Comisión en aquella etapa ${ }^{7}$. En medio siglo, ha sido el Parlamento del continente que ha evolucionado más, pasando de ser una asamblea consultiva a compartir el poder legislativo y presupuestario con el $\mathrm{CONS}^{8}$.

La primera etapa tuvo dos fases: 1952-70: Asamblea consultiva; 197079 autoridad presupuestaria compartida con el CONS para financiar la naciente política agrícola común (PAC). El acuerdo se logró en 1969 a la vez que se decidía la apertura de negociaciones con Gran Bretaña, Dinamarca, Irlanda y Noruega, iniciar la Unión política y monetaria así como la cooperación en política exterior. Se reemplazaron las contribuciones nacionales para financiar las políticas comunitarias por un sistema de «recursos propios». El acuerdo sobre quién debía controlarlos y asignarlos fue fijar el techo de ingresos por los EE.MM. y distribuir los gastos por decisión conjunta del PE y el CONS.

${ }^{6}$ Debates de la Asamblea Común, septiembre de 1952, p. 21.

7 OLIVIO, B., L'Europe difficile, Folio Histoire, Gallimard, Paris. 1998, pp. 54 y ss.

${ }^{8}$ HIX, Simon V. y otros, Fifty Years on: Research on the European Parliament en Journal of Common Market Studies, 2003. 2. pp. 191-202; MAURER, A.,Parlamentarische Demokratie in der EU, Nomos. Baden Baden, 2002, pp. 22-5. 
En 1974, el Consejo Europeo, creado por iniciativa del Presidente Giscard d'Estaing adoptó un acuerdo decisivo para democratizar la Comunidad: la elección del PE por sufragio universal a partir de 1979.

En esta etapa, se configuraron dos elementos clave para la codecisión: el primero, considerar al PE y al CONS como las dos ramas de la Autoridad presupuestaria en pie de igualdad, ratificada por Sentencia del Tribunal de Justicia. El segundo fue la creación del comité de conciliación para resolver las divergencias presupuestarias del PE con el CONS, aunque éste siguiera teniendo la última palabra.

\section{II.2. El PE elegido (1979-2011)}

\section{II.2.1. 1979-1993}

La segunda etapa es el PE elegido por sufragio universal simultáneo en todos los EE.MM. El período 1979-1986 se caracterizó por dos hechos relevantes: primero, el PE ejerció por tres veces su poder de rechazo del presupuesto. El segundo acontecimiento fue la elaboración por el PE de un Proyecto de Tratado sobre la Unión Europea. En él mismo se definía la autoridad legislativa (PE y CONS ejercen conjuntamente el poder legislativo con participación de la Comisión) la ley, la jerarquía normativa y el procedimiento de votación. El proyecto, bautizado según la tradición europea con el nombre de su ponente, el federalista italiano Altiero Spinelli, se basaba en una filosofía de Asamblea constituyente que no prevaleció, aunque tuvo enorme valor a la hora de inspirar las reformas sucesivas.

En el período 1987-92 se introdujo con el Acta Única Europea (AUE) el procedimiento de cooperación, que añadió una segunda lectura a la consulta, en la que la posición común del CONS se remitía al PE. Además, el PE consiguió el dictamen conforme en pie de igualdad con el CONS en la ratificación de los Tratados de Adhesión y Asociación.

El Acta Única fue tan eficaz como infravalorada al principio. El liderazgo político del recién elegido Presidente de la COM, Jacques Delors, fue decisivo para lograrla. Su ambicioso programa retomó el proyecto inacabado del mercado común, enriquecido con nuevas políticas - cohesión económica y social, política industrial e investigación, cooperación monetaria y convergencia de las economías de los EE.MM. - con el objetivo 92 para culminar el mercado interior.

El procedimiento de cooperación, aplicado inicialmente sólo a diez materias, tuvo impacto inmediato, al utilizarse para aprobar el «objetivo 92» (el paquete de 300 directivas del mercado interior, la reglamentación de los fondos estructurales y los programas de investigación). 
La caída del muro de Berlín en 1989 fue un salto cualitativo en el proceso en curso de realización de la Unión Económica y Monetaria ampliándolo a la Unión Política. El hecho, tan deseado por unos, como temido por otros, supuso el final de la guerra fría y llevó a una ola de ampliaciones, comenzando por la más sensible en términos políticos, la unificación alemana, tramitando por vía de urgencia de la integración de los nuevos Länder del Este, de la extinta República Democrática Alemana.

\section{II.2.2. De La CE a la UE (1993-2011)}

El Tratado de la Unión Europea (TUE), conocido como Tratado de Maastricht, supuso en 1993 un salto cualitativo, al transformar la Comunidad en Unión. Su objetivo inicial desde la Cumbre de Hannover de 1988 era la Unión Monetaria, pero los acontecimientos políticos de 1989 forzaron la agenda, introduciendo la Unión Política, con el reforzamiento de la legitimidad democrática, la eficacia institucional y la Política Exterior y de Seguridad Común (PESC).

En la gestación del Tratado, el PE consiguió, por primera vez, establecer un diálogo con el CONS y los Gobiernos, a través de la Conferencia Intergubernamental Preparatoria (CIP) y una plataforma común con los Parlamentos nacionales en la Conferencia de Roma de octubre de 1990 . He relatado mi contribución como Presidente del PE en mi libro «Europa en el alba del milenio» y mi conferencia «Berlín, de muro a puerta»9.

Los dos grandes avances del Tratado de Maastricht fueron: la ciudadanía europea, permanente aspiración del PE y la moneda única, el ECU - rebautizada como EURO - con la creación del Banco Central Europeo (BCE) y el proceso de convergencia. Además, el PE logró un sustancial incremento de sus poderes con:

- La codecisión legislativa, que desarrolló la cooperación con la inclusión del comité de conciliación para negociar compromisos entre el CONS y el PE. El procedimiento se aplicaba a 15 ámbitos relacionados con el mercado interior ${ }^{10}$.

9 BARÓN CRESPO, E., Europa en el alba del milenio. Ed. Acento, 1994; Berlin de muro a puerta, www.socialistsanddemocrats.eu/.../3554_ES_baron_crespo_berlin_wall_ en_101006.pdf

${ }^{10}$ En mi discurso ante el Consejo Europeo de Maastricht el 9 de diciembre de 1991 expresé la posición del PE en los siguientes términos:

La Comunidad, en su juego institucional, debe igualmente responder a la exigencia democrática fundamental de la doble legitimidad del doble voto de los ciudadanos. Nuestro postulado es simple: organizar las relaciones del PE y el CM sobre la base del poder legislativo compartido, la codecisión legislativa. Se trata de una piedra angular de 
- El derecho de votar al Presidente de la COM y al Colegio, con la modificación de su mandato de 2 a 5 años, coincidente con la legislatura, al Presidente del BCE y al Defensor del Pueblo Europeo.

El Tratado supuso un cambio importante en relación con el equilibrio institucional. Desde el punto de vista de la legitimidad formal, los Tratados creadores de la Comunidad la tenían al ser ratificados por los Parlamentos de sus EE.MM. En cuanto a la legitimidad social, se criticaba a la $\mathrm{COM}$ como un poderoso órgano de funcionarios no elegidos, al CONS por acumular poderes legislativos que no tenían sus miembros a nivel nacional, ejercidos de hecho por el Comité de Representantes Permanentes (COREPER) auténtico gobierno en la sombra de celosos diplomáticos, y el PE una mezcla de feria trashumante y Asamblea onusiana.

Crítica sobre la legitimación social de la Comunidad que se sintetizaba en la paradoja: «si la Comunidad solicitara su ingreso en sí misma, no sería admitida por no ser democrática». De hecho, entre las diferentes interpretaciones políticas y doctrinales existe, como señala Maurer, «un punto de consenso mínimo en constatar que el PE es una estructura singular que se distingue en solitario tanto de las estructuras parlamentarias estatales constituidas como de las organizaciones internacionales» ${ }^{11}$.

El vendaval histórico producido por el final de la guerra fría cambió una agenda que preveía, primero, la Unión Económica y Monetaria, y sólo al comienzo del nuevo siglo, la Unión Política. Como dijo Vaclav Havel «el mundo, el ser y la historia se rigen por un tiempo que les es propio, en el que podemos intervenir de modo creativo pero que nadie domina por completo».

En un momento telúrico como el final de la guerra fría, los líderes estuvieron a la altura de las circunstancias al considerar la urgencia de reforzar la doble legitimidad democrática. El Tratado, al incorporar la ciudadanía europea y hacer participar al PE en la investidura del Presidente de COM, colocó al ciudadano en el centro del sistema con un doble voto; por un lado, en las elecciones legislativas en su propio país, origen del Gobierno representado en el CONS; por otro, en las elecciones europeas, que adquirieron sentido al enlazar legislatura del PE con mandato de la COM, al tiempo que

la Unión Europea. No pueden ponerse en común atributos de la soberanía tan esenciales como los que implican la UEM y la Unión Política sin aceptar conferir al PE el papel y los poderes que en toda estructura democrática le son propios.

11 MAURER, A., Die Macht des Europaïsches Parlaments, SWP-Studie Stiftung Wissenschaft \&und Politik S 11 april 2004 Berlin, p. 7, y Parlamentarische Demokratie in der Europäischen Union, Baden Baden 2002. 
se establecía un poder legislativo compartido entre los dos brazos elegidos - PE y CONS - con la codecisión.

La codecisión como método legislativo supuso profundos cambios en la cultura institucional, creando una nueva dinámica basada en la doble legitimidad de la Unión Europea. La instauración del EURO como moneda única, fue un paso decisivo no sólo en el campo económico, sino como valor social en la vida cotidiana de todos los ciudadanos.

A partir de entonces, ha habido un ritmo de reformas cada 4 años. El proceso de ampliación se aceleró, con la entrada de Austria, Suecia y Finlandia en 1994, seguida de Chequia, Polonia, Eslovaquia, Eslovenia, Hungria, Estonia, Letonia, Lituania, Chipre y Malta en 2004, así como Rumanía y Bulgaria en 2007 .4 años.

El paso siguiente fue el Tratado de Amsterdam en 1999. Sus principales cambios fueron: ampliación del campo de la codecisión, más equilibrada para el PE; y el carácter vinculante de la votación de investidura del Presidente de la Comisión. Después, el Tratado de Niza añadió algunas competencias a la codecisión, complicó aún más la mayoría cualificada en el CONS y posibilitó la entrada de 10 nuevos EE.MM.

\section{II.3. El papel del Tribunal de Justicia}

Una característica tan importante como poco valorada del proceso comunitario es el decisivo papel del Tribunal de Justicia al consagrar, desde su inicio, el principio del efecto directo por el que los ciudadanos de los EE.MM. pueden defender sus derechos a partir de normas jurídicas comunitarias claras, precisas y autosuficientes, invirtiendo la presunción normal en derecho internacional.

Dos Sentencias hicieron historia. La primera es la citada Sentencia «Van Gend Loos contra Nederlandse Administratie des Belastingen» 1963 (caso 26/62) ${ }^{12}$ sobre los efectos internos del Tratado en los ordenamientos jurídicos de los EE.MM., atribuyendo a los justiciables derechos individuales que el juez debe proteger. Línea jurisprudencial confirmada por la Sentencia 6/6413 en el caso "Flaminio Costa contra el ENEL».

En relación con la división de poderes y la existencia de un poder legislativo, ambas Sentencias contienen importantes aportaciones: la primera es la afirmación de que la Comunidad es un ordenamiento jurídico de nuevo

12 Recopilación de Jurisprudencia (R.J.). Edición francesa 1963 p .00003. Edición especial española 1961-1963,p. 00333. Eur lex. eurlex-helpdesk@publications.europa.eu

13 (R.J.) Edición francesa 1964, p. 01141. Edición especial española 1964-1966, p. 00099. Eur lex eurlex-helpdesk@publications.europa.eu 
tipo en Derecho Internacional, al ser «expresión de la naturaleza de la Comunidad Europea como una Comunidad de derecho de estados, pueblos y ciudadanos» ${ }^{14}$; lo cual comporta limitaciones a las soberanías propias de los Estados con carácter indefinido. La segunda es que este principio contiene en esencia la teoría de la doble legitimidad democrática, de Estados y ciudadanos, con la afirmación de su participación a través del PE. Además, supuso el establecimiento del principio de protección judicial efectiva a nivel comunitario ${ }^{15}$.

El Tribunal elaboró con prudente audacia desde el inicio de la andadura comunitaria, una jurisprudencia que configuró dos características básicas del ordenamiento jurídico europeo: su efecto directo y su primacía sobre los derechos de los EE.MM. La doctrina de la primacía significa que, en su propia esfera, el derecho comunitario prevalece sobre el nacional. Su consecuencia es la doctrina de los poderes implícitos sobre la capacidad de la Comunidad para concluir Tratados, así como sobre los derechos humanos, al arrogarse el papel de examinar las violaciones de los mismos por los demás poderes.

En la elaboración jurisprudencial son también importantes las aportaciones de los tribunales constitucionales de los EE.MM. El caso alemán tiene especial valor por la naturaleza de la República Federal nacida de la Ley Fundamental de 1948, que anclaba su legitimidad en el compromiso del pueblo alemán «de servir a la paz mundial como una parte igual de una Europa Unida» y configuraba su sistema político sobre la base de cuatro principios estructurales: democracia, Estado Federal (Bundesstaat), Estado de Derecho (Rechtssaat) y Estado Social (Sozialstaat).

No es casual que sea el Tribunal Constitucional alemán el que haya elaborado más jurisprudencia sobre la legitimación democrática entre el ordenamiento comunitario y el propio. Su Sentencia más relevante es la de 12 de octubre de $1993^{16}$ por la que se proclamaba la compatibilidad del Tratado de Maastricht con la Ley Fundamental, contestando dos cuestiones básicas: la naturaleza y extensión de la legitimidad democrática requerida por la misma para la acción de la Unión así como el grado en que el Tratado satisfacía tales criterios. En relación con la primera cuestión, el Tribunal consideró que la UE no podía proporcionar la legitimación democrática «en la

${ }^{14}$ RODRÍGUEZ IGLESIAS, G.C., «Reflections on the general principles of Community Law», en The Cambridge Yearbook of European Legal Studies, volume I, 1989, Hart Publishing 1999, separata

15 VILA, B., Lecciones de Derecho Comunitario Europeo, Ariel Derecho, Barcelona 2002.

16 Arret sur «Maastricht» du 12 oct 1993. 2 BvR 2134, 2159/92. Sur papier dans: Entscheidungssammlung des Bundesverfassungsgerichts (BverfGE) 89,155. Text sur un site nonofficiel: http://www.oefre.unibe.ch/law/dfr7BV089155.HTML 
misma forma « que el orden interno constitucional, con lo que reconoció, en principio, que lo que se considera como «gobierno democrático « no puede ser aplicado sin modificaciones, ya que en una Unión de Estados que «siguen siendo soberanos " hay más margen para que se adopten normas legales por un órgano ejecutivo formado por gobiernos de los EE.MM. que lo que se permitiría en el marco constitucional nacional (Cullen, 1995) ${ }^{17}$. No obstante, la Ley Fundamental establecía exigencias derivadas del papel central del derecho de voto ciudadano, lo cual significaba que «el Bundestag debe conservar atribuciones y competencias de importancia sustancial» .

En lo que respecta a la legitimación democrática de la Unión, el Tribunal consideró que la UE no era un «Estado Europeo» sino un «Staatenverbund», es decir, una asociación de Estados entre la federación y la confederación en la que los EE.MM. continúan siendo los «dueños del Tratado«. La Unión no posee la llamada «kompetenz-kompetenz«, es decir, la capacidad para crear competencias al seguir dependiendo de las transferidas por los Estados en contra de la línea de interpretación expansiva por parte del Tribunal de Justicia Europeo. La consideración sobre el papel del PE para procurar la legitimación democrática a nivel de la UE se condicionó a que adquiriera poderes más sustanciales de decisión, una legislación electoral uniforme y una «Unión cada vez más estrecha entre los pueblos de Europa«. Línea jurisprudencial confirmada en la Sentencia que autorizó la ratificación del Tratado de Lisboa obligando al Bundestag y al Bundesrat a cambiar su legislación y que ha seguido posteriormente.

En el caso español, la jurisprudencia del Tribunal Constitucional sobre la primacía del Derecho comunitario europeo se inició con la sentencia 28/1991"18: "a partir de la fecha de su adhesión, el Reino de España se halla vinculado al Derecho de las Comunidades Europeas, originario y derivado, el cual - por decirlo con palabras del Tribunal de Justicia de las Comunidades Europeas - constituye un ordenamiento jurídico propio, integrado en el sistema jurídico de los Estados miembros y que se impone a sus órganos jurisdiccionales».

El Tribunal de Justicia ha tenido un papel pionero para hacer de la Comunidad una Comunidad de Derecho ${ }^{19}$, al formular las doctrinas que «fi-

17 CULLEN, P.A., «Competing Legitimacy at European and National Levels», en The Changing Roles of Parliaments in the European Union, European Institute of Public Administration, Maastricht, 1995, pp. 61 y ss.

18 ST del Tribunal Constitucional Español sobre el reconocimiento del ppio. de primacia y de sus consecuencias, las sentencias de 28/1991, de 14 de febrero de 1991, publicación BOE 19910315, n. ${ }^{\circ} 64$.

19 Por su parte, el PE apoyó activamente el desarrollo del sistema jurisdiccional europeo, con la Resolución de 1993 presentada por el diputado Medina Ortega DO C 268 del 4.10.93, sobre «el papel del Tribunal de Justicia en el desarrollo del sistema constitucional de la Co- 
jaron la relación entre el Derecho Comunitario y el del Estado Miembro y convirtieron esa relación en indiferenciable de las relaciones jurídicas análogas en los Estados constitucionales federales, que, sin embargo, integraba a Estados Miembros que no sólo no estaban amenazados sino que resultaron favorecidos» ${ }^{20}$ en opinión del Prof. Weiler, eminente especialista americano.

\section{II.4. El salto constituyente}

La Constitución Europea fue el fruto del «Debate sobre el Futuro de Europa en 2004», propuesto en el controvertido Tratado de Niza. Su temario contenía cuatro cuestiones: la inclusión de la Carta de Derechos Fundamentales, el reparto de competencias, la simplificación de los Tratados y el papel de los Parlamentos Nacionales en la arquitectura europea. Propuesta superadora del método tradicional de reforma a través de Conferencias Intergubernamentales (CIG).

El PE y la COM propusieron a la cumbre de Laeken la convocatoria de una Convención modelada a partir de la que redactó la Carta de Derechos Fundamentales, con la participación de parlamentarios europeos y nacionales, gobiernos, CM y Comisión (también de los países candidatos) para preparar una propuesta coherente.

Tras más de un año de trabajo, la Convención preparó un proyecto de Constitución aprobado en el Consejo Europeo de Roma. El texto era claramente innovador sobre definición, ciudadanía derechos fundamentales, objetivos, competencias de la Unión, y establecía la jerarquía normativa (ley, ley marco, reglamento, decisión, recomendaciones y dictámenes). La codecisión se convertía en el procedimiento legislativo ordinario, ampliando de modo substancial - de 35 a 85 - el número de materias sometidas a la misma. Tras el naufragio de la Constitución, su normativa se recuperó en el Tratado de Lisboa.

\section{La codecisión legislativa}

La codecisión es el procedimiento legislativo ordinario de la UE. Establecida en el art. 189b del Tratado de Maastricht, hoy se regula en el

munidad Europea informe Rothley en nombre de la Comisión Institucional A 3-0228/93 del 6/7/93», GARZÓN CLARIANA, G., «Le rôle du Parlement Européen dans le développement de la Cour de Justice», separata en Une Communauté de Droit, Festchrift für RODRÍGUEZ IGLESIAS, G.C., BWV. Berliner Wissenschafts Verlag 2003.

20 WEILER, J.H.H., Europa, fin de siglo, Centro de Estudios Constitucionales, Madrid 1995, p. 26. 
art. 294 del Tratado de Funcionamiento de la UE (TFUE). De conformidad con dicho procedimiento, el CONS, en representación de los Gobiernos de los Estados miembros, y el PE, elegido por sufragio universal directo de los ciudadanos, adoptan la legislación de la UE conjuntamente y en pie de igualdad.

\section{III.1. Ámbito de aplicación}

El ámbito de aplicación del procedimiento de codecisión se ha ido extendiendo progresivamente desde su creación en el Tratado de Maastricht. Inicialmente, se aplicaba a 15 materias, en torno a un cuarto de los textos legislativos sometidos a examen parlamentario. En esencia, de la mayoría de las cuestiones relativas al mercado interior, protección de la salud y los consumidores, medidas culturales y educativas, el reconocimiento y equivalencia de diplomas y calificaciones, libre circulación de trabajadores, programa marco de investigación y redes transeuropeas.

El Tratado de Amsterdam incluyó nuevos campos como transporte, lucha contra el fraude, cooperación al desarrollo, política medioambiental, cooperación aduanera, no discriminación así como algunas medidas sociales y de empleo. El Tratado de Niza extendió la codecisión a 44 materias, incluyendo cooperación judicial en temas civiles, política industrial, la base jurídica para los partidos políticos europeos; y tres temas más, relativos al asilo, la inmigración clandestina y los refugiados, sujetos a decisión del CONS.

El Tratado de Lisboa extiende la codecisión a 85 materias y a todo el Estado de Gastos del Presupuesto. Se añaden nuevas bases legales en materias claves de la política comercial común (acuerdos comerciales bilaterales y multilaterales), libertad, seguridad y justicia, particularmente en lo relativo al derecho penal, agricultura y pesca, Europol, Eurojust y cooperación policial, liberalización de servicios en sectores específicos, medidas relativas a los movimientos de capital de terceros países, medidas para eliminar distorsiones en el mercado interior y sobre la utilización del Euro.

Además, incluye nuevos ámbitos sometidos a codecisión como son iniciativa ciudadana, inclusión de nacionales de terceros países, prevención de la delincuencia, salud pública, propiedad intelectual, deportes, investigación, política espacial, energía, turismo, protección civil, ayuda humanitaria y cooperación administrativa. Igualmente crea una cláusula de solidaridad en caso de ataque terrorista o catástrofe natural.

También pasan a ser objeto de codecisión el espacio de libertad, seguridad y justicia, lo cual permitirá actuar más eficazmente contra el terrorismo 
y el crimen organizado. La comunitarización de esta política queda garantizada a pesar de algunos «frenos de urgencia», en forma de recurso al Consejo Europeo de aquellos EE.MM. que consideren en riesgo sus intereses esenciales. El Reino Unido e Irlanda pueden solicitar excepciones en algunos protocolos específicos de modo que sean compatibles.

Los progresos en el ámbito de la PESC se concretan en la creación de la figura del Alto Representante como Vicepresidente de la Comisión, con la creación de un Servicio europeo de acción exterior. Se establece la personalidad jurídica de la Unión y se suprime la estructura de pilares.

\section{III.2. Funcionamiento del procedimiento legislativo ordinario}

La codecisión como procedimiento legislativo comprende tres fases: primera lectura, segunda lectura y conciliación, seguida de una tercera lectura. El procedimiento puede concluir en cada una de las fases si las dos ramas de la autoridad legislativa han alcanzado un acuerdo.

Si después de dos lecturas en ambas instituciones - CONS y PE-, éstas no han llegado a un acuerdo sobre un mismo texto se remite la cuestión a un Comité de Conciliación compuesto por igual número de miembros por cada una, que tiene como misión negociar un texto transaccional que a su vez debe ser sometido a la aprobación de ambas.

En su preparación, se examinaron en especial dos experiencias de derecho comparado por parte del PE. La primera es la del Congreso de los Estados Unidos, consistente en un sistema de Conferencias entre el Senado y la Cámara de Representantes, en el que se constituyen delegaciones «ad hoc» para cada caso, formadas esencialmente por miembros de las Comisiones competentes. La segunda es la alemana, basada en una comisión de conciliación general con miembros permanentes entre el Bundestag y el Bundesrat. La solución escogida por el PE fue un compromiso entre ambas, con tres Vicepresidentes del PE como equipo director estable, el Presidente y el Ponente de la Comisión parlamentaria competente como miembros natos.

Por parte del CONS hay un representante por Estado miembro. Además, pasa a decidir con mayoría cualificada como regla. Los EE.MM. disponen en los casos previstos en los arts. 48, 82 y 83 del TFUE de un «freno de emergencia» que suspende el procedimiento un máximo de 4 meses. En algunos casos específicos, las propuestas legislativas pueden ser formuladas por un grupo de EE.MM., una recomendación del BCE o el Tribunal de Justicia. Asimismo, los Parlamentos Nacionales tienen derecho a intervenir desde la presentación de una propuesta para pedir un examen de subsidiariedad en el plazo de ocho semanas. 
La posición institucional del PE se refuerza al reconocerse que adopta «posiciones» en ambas lecturas y no «opiniones». Además, las bases para la conciliación son las posiciones respectivas del PE y el CONS en segunda lectura.

\section{III.2.1. PRIMERA LeCTURA}

La primera lectura comienza con la transmisión simultánea por la COM de su propuesta legislativa al PE y al CONS. La Presidencia del PE procede a asignar el proyecto a la Comisión parlamentaria competente sobre el fondo, teniendo las demás derecho a dar su parecer. En caso de contestación, la cuestión se somete a la Conferencia de Presidentes de Comisión, y en caso de que no haya acuerdo, a un equipo de tres Vicepresidentes, con la Conferencia de Presidentes de Grupo como última instancia. El tema tiene importancia, por las consecuencias de la diferente consideración de su base legal (p. ej. entre las Comisiones de Medio Ambiente y Económica sobre la responsabilidad financiera por daños medioambientales) Para resolver la compleja casuística se crearon los procedimientos Gomes, Hughes y Hughes reforzado, para compatibilizar el respeto al papel de cada Comisión con la coherencia del conjunto.

La Comisión competente procede a nombrar ponente del informe. $\mathrm{Su}$ trabajo consiste en preparar un informe o enmiendas al articulado en nombre del PE. Marca el calendario y ritmo de trabajo, teniendo presente la urgencia si la han solicitado la COM o el CONS o si está comprometida en el programa legislativo anual pactado PE-COM. Para realizarlo, cuenta con la secretaría de la Comisión, funcionarios de su propio grupo y sus asistentes. Para la información, pueden utilizar los servicios del PE, solicitarla a la COM, al CONS y a los gobiernos, organizar en casos importantes audiencias, hacer visitas con su dotación anual o entrevistarse con interlocutores económicos y sociales. Relación que plantea el papel e influencia de los representantes de intereses sectoriales, los grupos de presión o «lobbies», en el proceso legislativo. Su regulación se inició en el PE bajo mi Presidencia, culminando en un acuerdo común entre PE y COM en 2011.

El ponente se nombra a partir de negociaciones entre los coordinadores de los grupos parlamentarios sobre la base de su respectivo tamaño. El coordinador es una figura importante en el funcionamiento cotidiano del PE. Normalmente elegido en competencia abierta entre los miembros de su grupo, su función es dirigir la línea política, distribuir los informes, proponer enmiendas y modificaciones en nombre del grupo y preparar las lista de voto para su Grupo previamente al Plenario de la Eurocámara. Tarea en la que hay que combinar capacidad de liderazgo y sensibilidad política. Su pa- 
pel es tan relevante en la práctica que incluso fueron citados como interlocutores en un anexo de las Conclusiones del Consejo Europeo de Niza a pesar de no tener un «status» legal.

La estructura de un informe legislativo se compone de una propuesta de resolución cuyo elemento central es la aprobación o rechazo del proyecto, con o sin modificaciones. También incluye como elementos centrales la aprobación de la base legal del proyecto, formalidad, que adquiere decisiva importancia si el PE la contesta (p. ej., si considera que la cuestión es de codecisión en vez de simple consulta) o ser reconsultado en caso de cambio sustancial o que se abra el proceso de conciliación de $1975^{21}$.

La tarea del ponente es lograr, primero, el apoyo de la mayoría de su propia Comisión y después del Pleno. Puede expresar sus propias opiniones en la explicación de motivos, aunque si es muy partidista, cabe cuestionarla. A veces el ponente, ante el rechazo a sus planteamientos o los cambios en el texto, prefiere dimitir. El caso más delicado se produce cuando el ponente gana por estrecha mayoría en comisión, con el riesgo de perder las votaciones en puntos clave en Pleno. Cuestión especialmente sensible en la segunda lectura en codecisión y en el presupuesto, que lleva a tácticas como preparar baterías de enmiendas en primera lectura para tener elementos de negociación en la segunda.

En este sentido, el funcionamiento del PE es muy diferente al de los Parlamentos de los EE.MM. en los que la mayoría gubernamental - de un solo partido o de una coalición - impone su ley y se parte del supuesto de que las propuestas del Gobierno serán aprobadas. En el PE no existe tal mayoría progubernamental ni un grupo dominante, sino una amplia coalición formalizada sólo en la votación de la investidura de la COM y la aprobación del programa legislativo anual. En el día a día, las mayorías se configuran caleidoscópicamente en cada proyecto legislativo o resolución. Mientras que el trabajo del ponente es conseguir representar a la mayoría del PE, el de los coordinadores es lograr apoyo suficiente para las enmiendas que respondan mejor a la línea de su respectivo grupo, con una dialéctica continua programa europeo-intereses nacionales entre una estructura común federativa y sus delegaciones nacionales (los dos grandes grupos, populares (PPE) y socialistas ( $\mathrm{S} \& \mathrm{D}$ ) tienen miembros de prácticamente todos los países).

El PE aplica en su organización la filosofía de representación de los ciudadanos europeos como tales, por lo que se estructura por Grupos políticos, El Reglamento establece que «los diputados podrán organizarse en

21 Procedimiento escasamente utilizado hoy (sólo una vez en la legislatura 1999-2004 para modificar el Reglamento Financiero) pero de enorme valor histórico como precedente de la conciliación, al iniciar los contactos directos CM-PE. 
Grupos de acuerdo con sus afinidades políticas» (art. 30). En principio, se considera que la afinidad proviene de pertenecer a la misma familia política, encarnada en los Partidos Europeos, reconocidos en el Tratado de Maastricht y con existencia legal desde el Estatuto de 2003. La valoración de la afinidad adquiere importancia en caso de contestación, como ocurrió con la oposición mayoritaria a la creación de un Grupo Técnico entre los radicales italianos y el Frente Nacional en la legislatura 1999-2004. El Tribunal de Primera Instancia falló a favor de la necesidad de afinidad política como criterio necesario para su creación.

El artículo 30.2.del Reglamento del PE establece que «todo Grupo político estará integrado por diputados elegidos en al menos una cuarta parte de los EE.MM. El número mínimo de diputados necesario para constituir un grupo político será de veinticinco». La redacción de este apartado contiene implícitamente la prohibición de crear grupos exclusivamente nacionales.

El proceso de formación de la voluntad común en el seno de los grupos exige permanente disponibilidad para el debate y la transacción, dado que no existen normas de disciplina ni sanciones como en los Parlamentos nacionales. Se reconoce el voto de conciencia, con interpretación más bien lata. Hay que tener en cuenta que en los grandes grupos conviven diputados miembros de Partidos en el Gobierno en sus respectivos países con otros que están en la oposición en los suyos.

Una vez aprobado en comisión, el ponente defiende su informe ante el Pleno, expresando su criterio sobre las enmiendas presentadas. Su labor llega en su caso hasta la conciliación, de cuyo comité es miembro de oficio. En la práctica, algunos ponentes acaban siendo permanentes sobre un tema por razones de especialización.

El PE emite su informe en primera lectura sobre la propuesta de la Comisión. El CONS adopta el acto propuesto si aprueba todas las enmiendas del PE o si no las hay. Si el CONS no está plenamente de acuerdo con el texto legislativo aprobado por el PE, establece una posición común en su primera lectura. No hay plazo fijado para ambas instituciones, lo cual da margen para negociar las enmiendas.

\section{III.2.2. SEGUNDA LECTURA}

La segunda lectura supone un cambio sustancial. En un plazo de tres meses a partir de la comunicación de la posición común del CONS, el PE debe aprobar, rechazar o modificarla. En caso de aprobación, el acto será adoptado, sin necesidad de nueva confirmación expresa por parte del CONS. En caso de rechazo por mayoría, el procedimiento decae. Si el PE enmienda y modifica la posición común, el texto vuelve al CONS, que dis- 
pone de tres meses para decidir. Si acepta todas las enmiendas, el acto se considera aprobado; de no hacerlo, se procede a convocar el Comité de Conciliación.

La lógica de la segunda lectura es diferente a la primera al necesitar las enmiendas a la posición común la mayoría absoluta para ser aprobadas, lo cual provoca a veces situaciones equívocas como anunciar el Presidente de sesión que el texto ha sido adoptado por mayoría simple y tener que rectificar sobre la marcha. En principio, la única fórmula que garantiza la mayoría es el acuerdo PPE-S \& D, sin defección de sus delegaciones nacionales más importantes y con suficiente presencia de miembros. También cabe configurar mayorías con aportaciones de los demás grupos, especialmente liberales y verdes. Para lograrlo, se concentran las votaciones a mediodía los días centrales del pleno en Estrasburgo (martes y miércoles, a mediodía), o al final del pleno de Bruselas (jueves).

\section{III.2.3. CONCILIACIÓN}

La conciliación y tercera lectura es la fase definitiva del procedimiento de codecisión. El Comité de Conciliación es un órgano interinstitucional paritario integrado por representantes del PE y del CONS con la misión de conseguir un acuerdo sobre un texto conjunto, partiendo del examen de la posición común y las enmiendas del $\mathrm{PE}$ en segunda lectura, en un plazo de seis semanas después de la notificación oficial del CONS de que no puede aceptar todas.

Se constituye «ex profeso» para cada propuesta legislativa que requiera conciliación. Se compone de dos delegaciones: la del CONS, integrada por los Ministros o sus representantes, y la del PE, integrada por eurodiputados en igual número. La COM hace de «hombre bueno» para aproximar posiciones.

El período de seis semanas entre la segunda lectura del CONS y la convocatoria del Comité de Conciliación sirve para negociaciones informales. El Comité dispone de otras seis semanas tras su primera reunión para elaborar un «texto conjunto». Si no se alcanza un acuerdo o si el PE o el CONS no lo aprueban se considera el acto no adoptado. Los diferentes plazos son prorrogables a iniciativa de las instituciones. La delegación del PE se designa «ex profeso» para cada procedimiento de conciliación, según el peso político relativo de los grupos. Son miembros permanentes tres Vicepresidentes del PE, actuando uno como presidente; el ponente y el presidente de la comisión parlamentaria competente para el fondo son miembros de oficio.

La delegación del CONS está compuesta, en principio, por los Ministros o Secretarios de Estado de los EE.MM. La práctica habitual es la pre- 
sencia del titular del Gobierno que ejerce la Presidencia mientras que el resto son normalmente los representantes permanentes adjuntos de cada país (COREPER I). La ausencia de responsables gubernamentales no es sólo una cuestión formal, sino que afecta a su responsabilidad política ante sus propios Parlamentos. Cuestión que adquirirá importancia con la generalización de sesiones públicas del CONS en su función legislativa.

El Triálogo, trílogo o Diálogo a tres bandas es un tipo de reunión informal que se ha impuesto en la práctica como uno de los elementos más operativos del proceso. Cuando el CONS está en condiciones de presentar su dictamen sobre las enmiendas del PE, haya concluido o no oficialmente su segunda lectura, se organiza una reunión informal entre PE, CONS y COM.

Cuando el Comité de Conciliación ha alcanzado un acuerdo, se elabora un proyecto de texto conjunto (PE - CONS) redactado en una lengua que da fe y se traduce a continuación a las demás lenguas oficiales. Una vez revisado por los juristas-lingüistas, los copresidentes del Comité lo envían junto con una carta de remisión, que sirve de acta del procedimiento de conciliación, al incluir las declaraciones realizadas. Tras la aprobación, los Presidentes del PE y del CM firman el texto conjunto. En la primera firma en 1994, se acordó designar dichos textos legislativos textos «LEX».

\section{Balance de la codecisión desde el PE}

La experiencia de casi dos décadas de funcionamiento de la codecisión legislativa permite hacer un balance sobre el progresivo desarrollo del poder legislativo compartido en la Unión ${ }^{22}$.

El CONS dominó la función legislativa durante más de 40 años, desde la creación de la CECA hasta el Tratado de Maastricht, a iniciativa de la COM y con creciente presencia del PE, pero manteniendo su responsabilidad final como único autor del acto legislativo. En consecuencia, tenía un

${ }^{22}$ En la elaboración de este balance he utilizado, además de mi Conferencia Is co-decision bridging the EU's democratic gap, pronunciada el 16/10/2000 en la Asociación «Friends of Europe» en Bruselas, los completos informes anuales de los tres Vicepresidentes del PE encargados de las Delegaciones en el Comité de Conciliación así como el informe correspondiente a la V. ${ }^{a}$ Legislatura (1999-2004), disponibles en www.europarl.eu.int, así como los excelentes análisis publicados por Michael SHACKLETON, «The Politics of codecision», en Journal of Common Market Studies, vol. 38, n. ${ }^{\circ} 2$, june 2000, y del mismo, en colaboración con R. CORBETT y F. JACOBS, The EP at fifty: a view from the inside, vol. 41, n. ${ }^{\circ}$, abril de 2003; los trabajos de H. FARRELL y A. HÉRITIER, en especial, «The invisible transformation of Codecision», SIEPS, julio de 2003; y de S. HIX, «Constitutional Agenda setting... why EP won at Amsterdam», British Journal of Political Science, 2002, 32 (2), además de la bibliografía contenida en el anexo correspondiente a codecisión. 
profundo escepticismo sobre la capacidad del PE, que supuso un tenso inicio de la misma y permitió hablar de «traumatismo psicológico del CONS» (Rufas, 2004). Por su parte, el PE, en razón de su pasado como órgano fundamentalmente consultivo, tenía costumbres «maximalistas». La introducción del procedimiento de codecisión legislativa constituyó fue una ocasión única para compartir responsabilidad y disciplina de trabajo.

Para examinar el alcance de los cambios, es útil proceder, en primer lugar, a un análisis cuantitativo de la legislación aprobada, seguido por el cualitativo de las modificaciones en el debate parlamentario y la evolución de las conciliaciones, con particular atención a algunos casos relevantes.

\begin{tabular}{ccccc}
\hline & Total codecisión & $1 .{ }^{\mathrm{a}}$ lectura & $2 .{ }^{\mathrm{a}}$ lectura & 3. ${ }^{\mathrm{a}}$ lectura \\
\hline $1994-1999$ & 165 & - & 99 & 66 \\
$1999-2004$ & 144 & $72 \%$ & $23 \%$ & $5 \%$ \\
$2004-2009$ & 177 & $28 \%$ & $50 \%$ & $22 \%$ \\
\hline
\end{tabular}

Fuente: PE.

Es de destacar la importancia central de la segunda lectura en la que se aprobaron en torno a la mitad de los proyectos y el valor creciente de la primera, con un cuarto y el resto en tercera lectura. El espectacular incremento de la primera lectura ha llevado a Dehousse a pensar que existe una desviación del procedimiento ${ }^{23}$. Sin embargo, la calidad es tan importante como la calidad, ya que alrededor del $35 \%$ de los expedientes aprobados en primera lectura eran codificaciones, comitología o revocaciones.

Un valioso elemento de análisis sobre el funcionamiento del procedimiento de codecisión es el destino de las enmiendas del PE. Hasta 2004, el número de enmiendas del PE aceptadas por el CONS sin modificación en segunda lectura era estable, en torno al $23 \%$, las enmiendas objeto de transacción eran mayoritarias, el 60\%, y las retiradas por el PE eran un $17 \%$.

Además, han ido creciendo las declaraciones anexas a los textos legislativos publicadas en el Diario Oficial, para su interpretación auténtica o expresar la COM o el CONS un compromiso de futuro. A pesar de las reservas formales sobre su valor, su abundancia da fe de su utilidad política.

Para valorar a fondo la codecisión no basta un mero análisis cuantitativo, conviene también considerar el proceso en términos cualitativos. El primer anuncio del cambio profundo que la codecisión introducía en el

${ }^{23}$ DEHOUSSE, COSTA \& TRAKATOVA, «La codecision et les accords précoces: progrès ou détournment de la procedure legislative?», Notre Europe, n. ${ }^{\circ} 84$. 
equilibrio institucional se produjo con el rechazo del PE, en 1994, de la posición común del CONS en el informe Read sobre «Telefonía vocal», al final del procedimiento de conciliación, debido a diferencias en torno a la protección de los consumidores y la comitología,

En el caso del Informe Rothley sobre Biotecnología, el problema fundamental fue el ético. En el Comité de Conciliación, el CONS aceptó las enmiendas del PE, sobre la imposibilidad de patentar el cuerpo humano o elementos del mismo, la terapia génica germinal y la protección de los animales. Un compromiso políticamente aceptable, acompañado de declaraciones de interpretación publicadas en el Diario Oficial, lo cual constituyó un precedente. La delegación del PE puso como condición que la COM se comprometiera a presentar una propuesta legislativa para garantizar a los agricultores obtener crías a partir de animales patentados sin tener que pagar al titular de la patente. La COM hizo una declaración en Pleno antes de la votación del texto conjunto, que ahondó las divisiones nacionales transversales, en especial entre los italianos, por considerar el enfoque del CONS sobre la patentabilidad demasiado permisivo. Finalmente, el acto no fue aprobado al no tener respaldo la mayoritario. En 1995, la COM remitió una versión revisada de la directiva al PE. Los contactos del ponente con el CONS lograron que en segunda lectura se aceptara la lógica sustancial del paquete de 40 enmiendas del PE. Los puntos más importantes y polémicos fueron las modificaciones genéticas humanas y la no patentabilidad del cuerpo humano.

El acuerdo en primera lectura sobre acceso a los documentos de las instituciones europeas, no necesitó siquiera adoptar una posición común. El PE aprobó un paquete de enmiendas, pero no concluyó la primera lectura al no votar la resolución anexa, con lo que dejaba clara su orientación política a una Presidencia sueca del CONS muy sensible a la transparencia. La añorada ministra Anna Lindh fue decisiva para cerrar el acuerdo.

Una conciliación considerada como ejemplo de equilibrio institucional y respeto de la subsidiariedad versó sobre las «redes transeuropeas de energía»(1996). Las divergencias se centraban en el papel del PE en la identificación de proyectos de interés común que para el CONS no incluían la lista del anexo. La COM acabó por defender la tesis del PE de que éste formaba parte del texto, por lo que su modificación requería codecisión. El Comité de Conciliación reescribió por completo el anexo con una lista de 43 proyectos de interés común que no mencionaba expresamente ciudades o regiones y dejaba en manos de la COM las especificaciones técnicas.

En el paquete «Auto-Oil» (1998), el objetivo era reducir los niveles de contaminación de las emisiones de vehículos de motor y mejorar la calidad de los combustibles. En este caso, se entremezclaban los intereses de las industrias automovilística y petrolífera, la defensa del medio ambiente y los 
derechos de consumidores y usuarios. La conciliación cayó bajo una Presidencia británica muy presionada por su opinión pública y decidida a reducir las emisiones de $\mathrm{CO}_{2}$ en aplicación de los acuerdos recién adoptados en Kyoto. La transacción se hizo sobre los valores límite fijados en la posición común, con la condición de que fueran obligatorios en vez de opcionales.

La directiva sobre las OPA (Oferta Pública de Adquisición de Acciones) se aprobó en 2003, tras el rechazo del resultado de la Conciliación por el PE en un dramático empate tras doce años de gestación. Los contrarios al acuerdo, entre los que figuraba el ponente, el alemán Lehne (PPE), reprochaban al texto haber cedido en un punto esencial: la adopción de medidas de protección frente a las OPAs hostiles. Alemania se oponía a la propuesta, por estimar el Canciller Schröder que se desmantelaban los mecanismos de defensa de sus empresas frente a las mismas.

Tema complejo con trasfondo ideológico por el temor a un predominio sin límites del capital financiero sobre el industrial al eliminar defensas frente a los especuladores. También influyen las diversas filosofías sobre los sistemas de organización empresarial: el modelo anglosajón de mercado abierto y de «laissez faire frente al modelo continental del capitalismo renano. Defendieron el primer modelo los diputados británicos, mientras que en pro del segundo militaban los diputados alemanes, postura compartida por 6 de los 15 miembros de la delegación al considerar el resultado demasiado alejado de las enmiendas del PE. La votación en Pleno, con el criterio en contra del ponente, arrojó un empate de 273 votos. La Presidenta del PE, tras anunciar que la conciliación había sido aprobada, tuvo que corregir y rechazarla en aplicación del Reglamento. El desglose de votos reflejó la división en los dos grandes grupos con una ligera mayoría de votos contrarios y diferencias entre delegaciones nacionales, con postura favorable de británicos, daneses, suecos, finlandeses, portugueses, irlandeses y luxemburgueses frente a la contraria de alemanes, austriacos, griegos y belgas y la división de españoles, italianos y franceses. Además, las patentes presiones de última hora de algunos gobiernos sobre sus respectivos diputados agravaron la confusión.

En 2003, el PE y CONS llegaron a un acuerdo que modificó seriamente la propuesta de la COM, dejando en manos de los EE.MM. el poder de decisión sobre las medidas defensivas y los derechos de voto múltiple. En un sistema federal como EEUU existen legislaciones diversas según los Estados, con mecanismos de defensa que hacen que Delaware sea la sede de importantes multinacionales ${ }^{24}$.

${ }^{24}$ CIOFFI, J.W., The collapse of the EU directive on Corporate takeovers: the EU, national politics and the limits of integration, University of Berkeley, Round Table on the international economy, discussion paper 2001. 
La consolidación de la codecisión ha llevado a casos interesantes de reescritura por el PE de propuestas de la COM en la pasada legislatura. El primero es la Directiva de servicios en el mercado interior (CE) 123/2006, tema muy controvertido en la campaña del referéndum de la Constitución en Francia, El texto fue reelaborado por el PE en un interesante proceso de interacción interinstitucional ${ }^{25}$. El Reglamento REACH (CE) n. ${ }^{\circ}$ 1907/2006 es la primera regulación del comercio, registro y control de productos químicos a nivel mundial, que generó un intensísimo cabildeo de lobbies, multinacionales y Gobiernos. El ponente, Guido Sacconi, definió el resultado como una síntesis equilibrada entre la industria química europea, la salud y el medio ambiente ${ }^{26}$.

Otro paso es la negociación de grandes paquetes legislativos como el de energía y cambio climático, 20/20/20: un 20\% de reducción de las emisiones de gases de efecto invernadero, un $20 \%$ de mejora de la eficiencia energética y un consumo de energías renovables de un $20 \%$ para 2020 . Un macroacuerdo conseguido tras once meses de negociaciones, antes del voto en primera lectura del PE con la Presidencia francesa sobre seis propuestas : régimen de comercio de emisiones de gases de efecto invernadero (GEI); esfuerzos compartidos para reducir emisiones; almacenamiento geológico de dióxido de carbono; $20 \%$ de energías renovables ; reducción de emisiones de $\mathrm{CO}_{2}$ de vehículos y de emisiones de GEI de carburantes.

En la presente legislatura, cabe destacar la aprobación en septiembre de 2011 del paquete de gobernanza económica que consta de seis medidas: prevención y corrección de desequilibrios macroeconómicos, del Pacto de Estabilidad con sanciones en caso de deuda o déficit excesivos, requisitos comunes para los presupuestos nacionales, vigilancia presupuestaria en la zona euro y coordinación de políticas económicas

Las decisiones en el marco de la codecisión se pueden clasificar en dos grandes categorías: reguladoras o distribuidoras. Las primeras tienen como objeto definir normas, bien para actuar contra actividades perjudiciales (p.ej. medidas medioambientales, calidad de los alimentos, tabaco), bien para promocionar las beneficiosas (calidad de los productos, control de las comisiones de la banca), mientras que las segundas tienen como objeto el reparto de fondos en los diversos programas. La determinación del nivel de influencia parlamentaria no depende sólo del tipo de decisión, sino de otras variables según Shackleton y Judge. Una es el nivel de legitimidad imputable a la UE en el seno del CONS; cuanto más bajo es, menos posi-

25 DOLVIC, J.E. y ODEGAARD, A.M., The struggle over the services directive: a case study of interinstitutional decision-making in the EU», Arena Center for European Studies. University of Oslo. In htpp//www.arena.uio.no/. $21 \mathrm{ps.}$

26 SACCONI, G., Reach Story. Guerini e associati. 2008. 
bilidades tiene el PE de influir. El ejemplo del servicio voluntario europeo, programa para posibilitar a nivel comunitario a los jóvenes un servicio sustitutorio del militar es clarificador. Tiene problemas de dotación de medios por afectar a .un elemento del núcleo duro de la soberanía en la mayoría de los EE.MM.

Otra variable es el grado de concentración de costes: en la directiva de protección de datos personales en 1997, el PE defendía que los ciudadanos mantuvieran su exclusión de los bancos de datos públicos sin costes. La existencia en Francia del sistema Minitel, con millones de abonados en el momento de privatización de France Telecom, hizo imposible su aceptación. Por el contrario, establecer un calendario escalonado permitió la aceptación de la directiva «Auto-Oil». La regla de oro es conseguir una solución que pueda ser presentada como europea, en la que ningún país aparezca como claro perdedor ante su opinión pública, lo cual no excluye el debate apasionado. La clave es saber conducir la elaboración de la norma con arreglo a las normas del arte dramático para lograr un desenlace aceptable para las partes. La habilidad de un presidente del CONS, la mano izquierda de un Comisario o el acierto de un ponente del PE pueden ser determinantes.

Ejemplos que muestran la importancia de la actitud y el momento político de la Presidencia en ejercicio del CONS en el procedimiento de codecisión y la confianza en que se respetará el acuerdo si cambia dicha Presidencia. Se trata de implicar a todas las partes en un continuo tejer y destejer tanto en el seno del PE como del CONS. El proceso es muy dialéctico, no se puede planificar de antemano, hay que manejar atentamente su evolución, los compromisos y concesiones para llegar al resultado final.

\section{Relaciones con la Comisión}

También la COM se vio obligada a revisar su papel en el nuevo contexto interinstitucional de la codecisión. Mantiene su monopolio de poder de iniciativa en las dos primeras lecturas, en las que puede retirar su propuesta y si apoya las enmiendas del PE, obliga al CONS a cambiar el texto por unanimidad. Por su parte, el PE ha separado en su Reglamento la votación de la propuesta de la COM y la del proyecto de resolución legislativa, lo cual le permite, entre ambas votaciones, pedirle que exprese «apud acta» su criterio sobre las enmiendas aprobadas, e incluso proponer su rechazo. El CONS puede pronunciarse, aunque normalmente no está presente. Si la respuesta de la COM es insatisfactoria o si no está en condiciones de dar su opinión, se puede aplazar la votación por dos meses prorrogables, ya que el PE no se expresa oficialmente hasta que vota el proyecto de resolución legislativa. 
Donde la COM tiene mayores dificultades para encontrar su lugar es en la conciliación al estar el PE y el CONS en relación directa. Se encuentra en «situación de desventaja estructural» según Anne Rasmussen, pese a lo cual «un análisis cuantitativo y cualitativo de la influencia legislativa de la COM muestra que ha ejercido de hecho una influencia considerable en el procedimiento» ${ }^{27}$. Las razones son varias: dispone de mejor información y conocimiento técnico; tiene las prerrogativas del Tratado y equipos funcionariales y por fin, ha visto la conveniencia de formar alianzas con el PE.

Otro problema son las quejas formales de la COM sobre la vulneración de su monopolio del derecho de iniciativa por los acuerdos entre PE y CONS, para que presente nuevas propuestas en un plazo determinado. La COM defiende su derecho a hacerlo si lo considera «apropiado», mientras que el PE trata de obtener compromisos más precisos, con apoyo del CONS normalmente. Su respuesta es reaccionar con un creciente número de declaraciones interpretativas unilaterales a los actos aprobados en conciliación. Esta inflación de declaraciones va claramente en contra del «Acuerdo interinstitucional sobre la calidad de redacción de la legislación comunitaria» de 1998, por el que «las declaraciones interpretativas no están previstas en modo alguno en los Tratados y son incompatibles con la naturaleza del Derecho Comunitario». Se consideran como un peaje de la COM para lograr el acuerdo final.

También existen declaraciones «ocultas», no publicadas en el Diario Oficial, como en el expediente «preparados peligrosos», donde la Comisión hizo una declaración a la posición común del CONS que no aparece en el texto conjunto.

Por fin cabe mencionar la saludable práctica introducida por la COM en su «Comunicación sobre retirada de propuestas que no tienen carácter de actualidad» de $2001^{28}$, en cuya virtud retiró 108 proyectos legislativos y no legislativos pendientes.

\section{El legislador europeo y la esfera pública}

En términos históricos, el balance de la codecisión es muy positivo. No obstante, hay aspectos críticos. La primera cuestión es cuál será la lógica predominante entre la intergubernamental del CONS y la deliberante

27 RASMUSSEN, A., «A strategic facilitator operating in a situation of structural disadvantage». «The role of the European Commission in co-decision», Dpt. of Political Science, University of Copenhague, marzo de 2001.

${ }^{28}$ COM (2001) 763 final. 
del $\mathrm{PE}^{29}$. Este debe evitar parecerse cada vez más a aquél en su forma de trabajar y defender el sistema parlamentario en el proceso legislativo Las condiciones esenciales para ello son: la publicidad de los debates y trabajos así como el acceso público a los documentos, que constituyen la transparencia como signo de identidad de la democracia ${ }^{30}$.

La transparencia, expresión clave en el debate político europeo actual, equivale al criterio de publicidad de «luz y taquígrafos» en nuestro lenguaje parlamentario tradicional. Habermas señala cómo la aparición de la esfera pública en la Europa moderna viene de la transformación del Parlamento estamental en un Parlamento moderno, que se produjo en Gran Bretaña a comienzos del siglo XVIII, tras la Gloriosa Revolución, con el ascenso de la burguesía comercial e industrial. Los hechos precursores fueron por un lado, la fundación del Banco de Inglaterra, la eliminación de la censura y el primer gobierno de gabinete responsable ante el Parlamento; por otro, la generalización de los cafés como «semilleros de agitación política» y la aparición de la prensa libre.

Al principio, el Parlamento se resistió a la publicación de sus debates y votaciones como garantía frente a la arbitrariedad real, pero fue precisamente la opinión pública de la naciente sociedad civil la que llevó, «al cambio cualitativo de la total publicidad de las deliberaciones parlamentarias» ${ }^{31}$. Habermas insiste que «no habrá remedio para el déficit de legitimación sin una esfera pública europea, una red que dé a los ciudadanos de todos los Estados Miembros igualdad de oportunidades para participar en un proceso incluyente de comunicación política común» ${ }^{32}$.

En el marco actual de la Unión Europea, sobre el fundamento del mercado interior se han afirmado los valores comunes en la Carta de Derechos Fundamentales y la organización de los poderes de una república compuesta, a «compound republic» por decirlo con Madison ${ }^{33}$. Construcción en la que convergen culturas políticas profundamente diferentes como son la tradición continental del Estado de derecho (Rechtssaat) y la británica del imperio de la ley (rule of law) ${ }^{34}$. Aunque la UE no es un Estado, aun-

29 «Informe de actividades del PE», en el Comité de Conciliación 2000-1, en particular Después del seminario: el enfoque intergubernamental del CM versus el enfoque parlamentario.

${ }^{30}$ Informe de actividades del PE en el Comité de Conciliación 2001-2, en particular Transparencia de los trabajos y acceso a los documentos, pp.11 y ss.

${ }^{31}$ HABERMAS, J., The structural transformation of the public sphere, Blackwell, pp. 57 y ss.

32 HABERMAS, J., «Why Europe needs a Constitution», New Left Review, septiembreoctubre de 2001, pp.5 y ss.

${ }^{33}$ The Federalist papers, n. ${ }^{\circ}$ 51.Bantam books.1982, p. 264.

34 PEREIRA, A.-C. Rule of Law o Estado de Derecho, Marcial Pons, 2003, p. 14. 
que el tema esté ya planteado jurisprudencial y doctrinalmente ${ }^{35}$, la cuestión es saber si estamos construyendo una federación, una confederación u otra forma novedosa. De momento, la respuesta es que el sistema político comunitario, tal como funciona es una República «sui generis», construida conjuntamente por representantes de ambas tradiciones políticas y jurídicas en continua ósmosis. Hasta el Tratado de Maastricht, el proceso de elaboración de decisiones del sistema político comunitario se caracterizaba por su opacidad, tanto en la COM como en el CONS. La introducción de la ciudadanía, con el reconocimiento de los derechos de petición y de acceso a los documentos, la investidura de la COM y la codecisión, colocaron la transparencia como elemento central del sistema.

Cuestión importante son las reuniones informales. H. Farrell y A. Héritier critican los problemas de legitimidad democrática que comporta esta "plétora de reuniones informales y semiformales en las que se adoptan muchas de las decisiones reales sobre la legislación, con escasas posibilidades de control público», aun reconociendo que «es muy difícil ver cómo se podría realizar el proceso legislativo sin triálogos o algo parecido» ${ }^{36}$. En relación con la legitimidad democrática, la respuesta sólo puede consistir en que los resultados sean públicos y susceptibles de verificación y contestación.

Esta cuestión conduce a la relativa a los riesgos de alianzas entre los Estados y sus diputados en el PE. La esencia del proceso comunitario es la aceptación de una voluntad común que va más allá del acuerdo entre Estados. La crítica más usual de la legitimidad democrática comunitaria es que no existe todavía un demos o pueblo europeo ni es previsible que lo haya. Hay que matizar con Constantin Stephanou que el lazo entre el demos (cuerpo de ciudadanos) y el etnos (nación) es reciente. En la Grecia clásica había tantos demos como ciudades, aunque los helenos tenían conciencia de pertenecer a una comunidad étnica fundada sobre una lengua, una religión y una civilización comunes; así, eran los únicos admitidos a participar en los juegos olímpicos ${ }^{37}$.

El debate sobre la ciudadanía y la Carta de Derechos Fundamentales en la CIG del Tratado de Lisboa es significativo para comprender la resistencia tenaz de algunos gobiernos. Fue preciso un emplazamiento por parte

35 GÖRLACH, W., LEINEN, J. y LINKHOR, R., Die EU ist eine staat. Documento de trabajo del Grupo del PSE.

36 FARRELL, H., \& HÉRITIER, A., «The invisible transformation of Codecisión: problems of democratic legitimacy», SIEPS, 2003: 7.

37 STEPHANOU, C., Les racines de l'identité européenne, Economica, Ed. De R. Dumont, p. 253. 
de la delegación del $\mathrm{PE}^{38}$ para que la ciudadanía europea, consagrada en el TUE de Maastricht, volviera al TUE y para que la Carta no se limitara a una simple Declaración. Ciudadanía europea que responde al «patriotismo constitucional» ${ }^{39}$, que «sólo puede desarrollarse conjugando interpretaciones diversas, impregnadas por las distintas historias nacionales, de unos mismos principios jurídicos universalistas». Suiza, plurisecular federación en la que conviven diferentes identidades culturales, es el ejemplo más cabal de esta «unidad en la diversidad», lema constitucional europeo ${ }^{40}$. Para Peces-Barba, esta idea de patriotismo constitucional «puede jugar un papel fundamental en la construcción de la Unión Política Europea» ${ }^{41}$.

En la doble legitimidad democrática, la representación de los intereses de cada Estado Miembro se hace en el CONS y la de los ciudadanos en el PE. Por eso, se establecieron en el CONS mayorías cualificadas y minorías de bloqueo, que van más allá del derecho de veto cuya sombra planeó largo tiempo con el «compromiso de Luxemburgo» como último recurso, aunque no tuviera «ninguna existencia, ni jurídica ni política» según Emile Noël ${ }^{42}$. La introducción de la codecisión representó un cambio de lógica para el CONS: La cuestión es como tomar conjuntamente decisiones más que paralizarlas.

La legitimidad del PE parte de representar a los ciudadanos. Aunque formado inicialmente por diputados elegidos a segundo nivel, se generó muy pronto una nueva realidad en la que los grupos parlamentarios del PE se organizaron sobre base plurinacional con la regla de la mayoría. La ruptura de la disciplina de grupo tiene efectos distintos en las dos lecturas: en la primera, lo importante es ganar, mientras que en la segunda hay que superar el listón de la mayoría absoluta.

En los grupos coexisten una estructuración federativa con delegaciones nacionales. Los dos mayores grupos - el PPE y el S \& D- con diputados de todos los países, funcionan con lógica federativa ${ }^{43}$. Las reuniones de je-

${ }^{38}$ Compuesta por los tres diputados: Elmar Brok, Andrew Duff y yo mismo.

39 HABERMAS, J., «Ciudadanía e identidad nacional», en Facticidad y validez, op. cit., pp. 619 y ss.

40 Tesis que desarrollé en mi artículo «En Europa cabemos todos», publicado por J. LABORDA \& Tomás FERNÁNDEZ, editores, en el libro España ¿cabemos todos?, Alianza Ed. pp. 83-101.

${ }^{41}$ PECES-BARBA, G., «Les valeurs de la culture politique européenne», op. cit., p. 130.

42 NOËL, E., «L'Acte Unique Europénne et le Développement de la CEE», op. cit.

43 Reforma que fue fruto del trabajo de un «grupo de sabios» presidido por el alemán Willy Görlach, que propuso un paquete de reformas consistente en la elección directa del Presidente por el Grupo, creación de un equipo de ocho vicepresidentes elegidos también directamente por el Grupo y no como hasta entonces, en donde el Presidente era propuesto en un paquete por el Partido europeo y los jefes de cada delegación nacional se convertían en vicepresidentes de modo automático. 
fes de delegación nacionales son decisivas al configurar el PE al comienzo y a mitad de legislatura, para nombrar los cargos tanto institucionales como políticos. Las negociaciones se hacen con la regla de D'Hondt, con margen para cohonestar preferencias. La lógica es cada vez más conceder competencias a la dirección elegida del Grupo, en cuya composición hay dosificar presencia igualitaria de ambos sexos, equilibrio entre Estados grandes y pequeños, Norte y Sur, así como veteranos y nuevos.

De hecho, se trata de un proceso de aprendizaje democrático cotidiano, en el que curiosamente se implican también los parlamentarios elegidos en listas antieuropeas, con una fuerza capaz de superar barreras idiomáticas y peculiaridades de diversos sistemas legislativos. La mejor definición del PE para el observador es la de una Torre de Babel que funciona, gracias a una síntesis innovadora de las mejores tradiciones parlamentarias europeas, servida por una compleja y eficaz organización de funcionarios, intérpretes y traductores.

¿Existen realmente legisladores europeos? Mi estimación personal es que se logran respuestas europeas en más del $80 \%$ de los casos, no por ignorar la propia problemática nacional sino por conseguir elaborar propuestas comunes. Incluso, una presión demasiado intensa de los gobiernos sobre los diputados de su nacionalidad puede generar efectos contraproducentes, Este es uno de los principales problemas de la relación entre los protagonistas de la codecisión y la esfera pública, porque normalmente las presiones llegan con dramatismo nacionalista en el último momento, difícilmente compatible con el proceso de mediación y aproximación comunitario. La regla de oro para intervenir en un proyecto legislativo es cuanto antes mejor, escogiendo los argumentos capaces de implicar a la mayoría frente a posturas numantinas de defensa de intereses vitales nacionales para justificarse en casa.

A conclusiones más radicales llegó el completo estudio realizado por Hix, Noury y Roland sobre las pautas de comportamiento de los eurodiputados a la hora de votar a partir del análisis de 11.500 votaciones nominales de más de 2.000 diputados en el período 1979-2001, desde su elección por sufragio universal ${ }^{44}$. Su principal conclusión es que el PE es un Parlamento normal en el sentido de que los resultados revelan un alto y creciente grado de cohesión en sus miembros a la hora de votar en la línea de sus grupos políticos, que pasó de una media del $82 \%$ en la legislatura 1979-84 al 84\% en 2001, y se elevó al $89 \%$ en el caso de los tres principales (populares, socialistas y liberales). A título de comparación, el porcentaje en el Congreso

${ }^{44}$ HIX, S., NOURY, A. y ROLAND, G., How MEPs vote y Power to the parties, cohesion and competition in the European Parliament, 1979-2001, London School of Economics, Université Libre de Bruxelles y University of California Berkeley, 2002. 
de los EE.UU. varió entre el 78 y el $82 \%$ en el mismo período. Asimismo, la principal línea de división y competición política se sitúa en torno al eje izquierda-derecha y no en relación con el origen nacional, con un grado creciente de cohesión en socialistas, liberales y verdes frente a populares, soberanistas e izquierda unida y una coincidencia mayor entre socialistas y liberales que entre éstos y populares. Los autores consideran que a la luz de los datos, la percepción que los medios de comunicación y parte de la doctrina tienen del PE está muy alejada de la realidad, perpetuando clichés estereotipados del pasado, y consideran que es notable este comportamiento en un PE que «no tiene mayoría gubernamental, con votos nacionales en el CONS y cambios en el poder». Las votaciones que sirvieron de base del estudio eran más amplias que las correspondientes a la codecisión, Tendencia creciente relacionada, sin duda, con la introducción del poder legislativo compartido.

\section{Conclusión}

En resumen, la codecisión como procedimiento legislativo ordinario ha adquirido carta de naturaleza como base de un sistema legislativo que funciona cada vez más como «un sistema clásico bicameral» ${ }^{45}$. De hecho, funciona frente a los malos augurios que se prodigaron en el momento de su introducción, ha contribuido de modo decisivo a cambiar las relaciones en el triángulo interinstitucional y reemplazado la genérica denuncia del déficit democrático por una praxis legislativa pública más en línea con la cultura política de los Estados miembros.

La consagración en el Tratado de Lisboa del poder legislativo compartido con el reconocimiento de la ley y la jerarquía normativa, ha abierto una nueva etapa. La necesidad de responder a la crisis económica fortaleciendo la Unión Económica y Monetaria, con la reforma del Tratado en ciernes para el paso a la Unión Fiscal, está acelerando de modo espectacular el proceso de consolidación de la UE como una la democracia supranacional.

45 HIX, S., «The political system of the European Union», Macmillan NY, 1999, p.56. 